\title{
Structural Equation Modeling of Separation Anxiety in Children Based on Maternal Anxiety, Mother-Child Relation, Maternal Attachment Style, Children's Incompatibility Schemas and Child Attachment Style
}

\author{
Zohreh Abbasi \\ PhD Candidate of General Psychology, Department of Psychology, University of Isfahan, Isfahan, Iran
}

Sholeh Amiri

Associate Professor, Department of Psychology, University of Isfahan, Isfahan, Iran Corresponding Author E-mail: s.amiri@edu.ui.ac.ir

\section{Houshang Talebi}

Associate Professor, Department of Statistics, University of Isfahan, Isfahan, Iran

\section{Doi:10.5901/mjss.2016.v7n4s1p54}

\section{Abstract}

Child separation anxiety is one of most common anxiety disorder that strongly influence educational activities, social compatibility and adult anxiety disorders. However, all combination factors never studied in a fully integrated approach. This study aim to investigate some determining factors of such disorder, entirely. It was hypothesized that childhood anxiety can be predicted by a sequence of factors directly or indirectly. A sample of 620 mother-child pairs (6 and 7 years old girls and boys) were selected. Cattle Anxiety Scale (CAS) for Adults, Mother-Child Relationship Scale, Adult Attachment Scale, Child Attachment Assessment Scale, Children Incompatible Schema Questionnaire, and Child Symptom Inventory, using selfreported data were collected. Data was analyzed by Structural Equation Modeling (SEM). Relative fitness index for fitted model was 0.741 and incremental fitness index was higher than 0.9. In the standard model, a significant causal relationship between maternal anxiety and mother-child relation was observed. Mother-child relation, itself, in two paths, have effect on separation anxiety disorder (SAD) through intermediate variables of maternal attachment style, child attachment style and children incompatible schemas. One of present study limitations is the use of correlation plan and a causal interpretation of its results. The second limitations was the self-reporting feature of research tools that showed the results of perception of the participant from the measured structures. The measured structures may be influenced by different cultural, individual and family values. The findings of this study showed that except for the negative impact of two intermediate variables, namely mother-child relationship on maternal attachment style, in two directions of model, the positive coefficient relations indicate a positive effect on intermediate variables and finally dependent variable.

Keywords: Child Separation Anxiety, Maternal Anxiety, Mother-Child Relationship, Maternal Attachment Style, Children Incompatible Schema, Child Attachment

\section{Introduction}

Anxiety disorders are the most common class of mental disorders that impact on the life of some children and adolescents. Anxiety results in child's avoidance of activities such as going to school, communication and contacting with peers and independent activities (Macsh \& Barkley., 2004). Among anxiety disorders, separation anxiety as a normal part of emotional evolution at the onset of childhood, sometimes indicate anxiety in a 12-year old child which is beyond common program and the scheduled principle of natural growth (Warner et al., 2009). Separation anxiety disorder is diagnosed only when the disturbed behavior continues more than usual for at least 4 weeks and leads to clinical injury or discomfort in important aspects of individual's function such as educational performance or social relation (Barra et al., 2014). Prevalence of separation anxiety disorder in children is about $4 \%$ and it has been reported that it is more in girls than boys (Waite, \& Creswell., 2014). Cavasagar et al., (2000) showed that symptoms of separation anxiety in children anticipate about $33 \%$ of variances of separation anxiety in adults which, in the case of no treatment, continues until adulthood and causes several problems for the individual. It is therefore concluded that anxiety disorders including separation anxiety in childhood may become chronic and durable. Thus, it is necessary to elaborate crucial effective 
factors in this disorder for rendering therapeutic intervention. (Chorpita et al., 2002; Waite, \& Creswell, 2015; Berek, 2001).

Emergence of different types of anxiety including separation anxiety in the course of child's development has been considered as a kind of object relations and especially mother-child relationship from different viewpoints and especially mental analysts. Therefore, this relation plays an important role in causing anxiety in children (Bowlby., 1969; Besharat., 2004). There are few researches related to separation anxiety which are focused on parental variables. Now, in consideration of adverse consequences of this disorder, its treatment is important. This stimulates the research to formulate a model based on statistical foundations such as SEM to understand separation anxiety factors. To explain separation anxiety disorder, the existing theories emphasize on understanding the mutual relation between parental factors and child in the context of environmental stressful factors (Chorpita et al., 1998) and they have showed it in the growth model of Manassiss et al., (1994). Parental behavior has a special importance in etiology and treatment of child's anxiety. As to parental and family effects in creating anxiety disorders, these studies emphasize on over control, over protection, modeling or improvement of anxiety or avoidance behavior, negative expectation al believes for the child, lack of positive and warm emotions, rejection and criticism, conflict and parental style. Chorpita \& Barlow., (2004; quoted by Aliov et al., 2012) believe that two aspects of mother's behavior that include warmness or sensitivity to children and stable responding as well as encouragement of children to autonomy and lack of attachment would result in children's sense of control and decrease of their anxiety. Therefore, there is a significant relation between psychological welfare of parents and children's mental disease including anxiety (Hoyt \& Flat., 2004; Berk., 2001; Babaei et al., 2008).

Mother-child relationship is the first and one of the most important relationships that contribute in different kinds of anxiety including separation anxiety in the development course of child. Moreover, mother's anxiety can result in child's anxiety (Bowlby 1969; Besharat 2004). Researchers such as Apetroaia et al., (2015); Turner \& Sander (2006); Muray and Johnston (2006); Oliver et al., (2009); Hassanabadi et al., (2012) have shown that training the parent-child relation can be effective in improvement of parents' behavior in communicating with children, increase of self-confidence, improvement and decrease of children's anxiety. The study conducted by Khodapanahi et al., (2012) showed that positive parent-child relations is the negative predictor of symptoms of anxiety disorders including social anxiety and obsession-compulsion and that mother-child conflict and mother-child attachment is the positive predictor of anxiety symptoms especially generalized anxiety.

A new orientation discussed in the mother-child relations is the theory of attachment (Rutter \& Eisenberg., 2010). Upon formation of attachment relations between mother and child, mother acts as the safe base and facilitator of search and emotional refuel of the child based on which the child look for new, challenging and unpredictable situations. Internal working model grows inside the child based on initial attachment experiences and influences on all other relations. Safety and healthy growth of child to one or more symbols of sensitive attachment result in emotional adjustment (Yapa, \& Jorm., 2015), self-control and problem solving skills (Brotherson., 2006). Lack of any opportunity for formation of attachment will result to clinical model of attachment disorder (Bowlby., 1969; Rutter and Esenberg., 2010). Aslani et al., (2013) showed in their studies that insecure attachment is directly associated with disorders such as depression and anxiety and that parents' insecure attachment would enhance the child's insecure attachment and would prepare the ground in the child to understand that the world is a dangerous place; in the manner that mother's attachment and her excessive care induce this message to the child that his/she is unable to face challenging (conflicting) situations. In this way, the child feels insecure and his/she anxiety is intensified (Zolfaghari Motlagh et al., 2008; Barber., 1996). With a view to these researches, it can be concluded that mother's attachment can be one of the factors contributing in insecure attachment and separation anxiety in the child.

Incompatible schemas are another factor which is associated with separation anxiety in the child. Noee et al., (2010) found parental roots for incompatible schemas. Those parents who do not let their child to assert his/her ideas and internal emotions and feelings, their children with incompatible schemas would become neurotic, anxious and distracted individuals in the future (Cai-Lian et al., 2012). The study conducted by Ghamkharfard et al., (2012) showed that children's schemas play a more highlighted role in anticipation of childhood anxiety. As cognitive elements, schemas play a role in personality organization and interpretation of individual experiences of events. Considering their attachment styles, the viewpoints exercised by parents against their children play an important role in the formation, growth and development of children in the first years of life and emergence of anxiety disorders. Findings showed that childhood anxiety is anticipated by failure, vulnerability, loneliness and submissiveness schemas in children. Now, considering the above evidence, the contributing factors should be addressed from the very childhood to prevent separation anxiety disorder in children.

Therefore, considering the short term and future goals including decrease or removal of separation anxiety disorder and decrease of accompanying mental injuries as well as long term objectives including prevention of separation 
anxiety (Lotfi Kashani, \& Vaziri., 2010), we can take a large step in this way by formulating a prediction model for separation anxiety based on variables including maternal anxiety, mother-child relation, maternal attachment style, child's incompatible schemas and child's attachment style. An assumed causal model is therefore depicted below for separation anxiety in children.

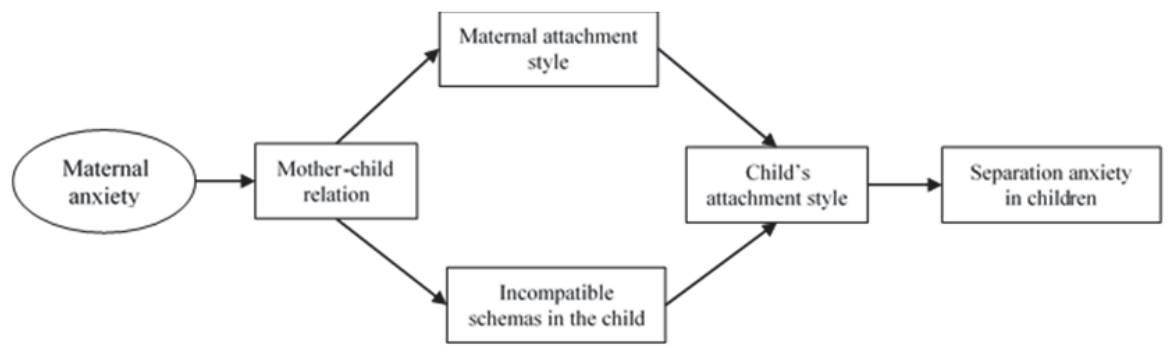

Figure 1. An assumed causal model for separation anxiety in children

Based on the reviewed researches and theoretical views for the variables affecting separation anxiety in children, efforts are made in this research to survey the priority of studied variables and to explain the structural model of separation anxiety in children.

\section{Method}

\subsection{Procedure}

Research Method, Statistical Society and Sample: This research is of fundamental type with respect to objective and is of descriptive and correlation type with respect to data collection method and is of quantitative type with respect to collected data.

\subsection{Participants}

Statistical society included 6 and 7-year old boy and girl students in preschool and first grade of elementary school in Qom city who studied in the school year 2013-2014 along with their mothers (26740 people). Since the goal is to prepare a SEM model and a large sample was required for his purpose (Arizi \& Farahani., 2008), 620 people were selected by dual stage classification and cluster sampling method, in the manner that educational zones of the city were considered as classes and some schools were selected from each class on a cluster basis and then the sample was specified from those schools based on their students ratio and after determining sample volume from Cochran formula.

\subsection{Measures}

Tools: The following tools were used to collect research data.

\subsubsection{Cattle Anxiety Scale (CAS) for Adults}

This scale is based on extensive studies and is applicable to both sexes from the age of 14 and higher and also in most cultures. Validity of this test, which has been fulfilled by its reimplementation for several times, has always been higher than $70 \%$. Therefore, this test can distinguish anxious individuals from normal people with a high confidence (Ganji., 2001). This questionnaire has 40 questions. Total scores of the first 20 questions and the next 20 questions should be specified separately. Total scores of the first 20 questions indicate a hidden anxiety and total scores of the second questions indicate an apparent anxiety. Subscales include Q3 with 8 items indicating lack of self-consciousness integration, $C$ with 6 items indicating general neuroticism L with 4 items indicating paranoid insecurity with 12 items indicating tendency in the sense of guile and Q4 indicating Argy tension with 10 items. 


\subsubsection{Mother-Child Relation Scale}

Mother Child relationship evaluation scale was developed by Robert M. Ross in 1961. This test is an attitude measuring scale by which the viewpoints of mothers concerning 4 styles of interaction with children are evaluated. Subscales of this test include 1) Accepting children, 2) Excess protection, 3) Leniency and 4) Exclusion of children (Zamiri., 2005). This scale is completely performed within 30 minutes. Experimental data for MCRE was obtained from an 80-people population of mothers. All the mothers were of middle class between 25 to 35 years of age. Reliability of MCRE test was evaluated by Zamiri., (2005) on 30 individuals and according to the calculated credit coefficients, the aforesaid test enjoys the required credibility. Moreover, validity of the test was confirmed by experienced professors and the test was recognized to be effective. Reliability: Pearson correlations had been used in the first half scale sores against the second half. The following table 1 shows reliability coefficients.

Table 1: Reliability coefficient

\begin{tabular}{cccc}
\hline Scales & $\mathbf{R}$ & $\mathbf{N}$ & $\mathbf{P}$ \\
\hline A & 0.57 & 80 & $\mathbf{0 . 0 1}$ \\
\hline OP & 0.53 & 80 & $\mathbf{0 . 0 1}$ \\
\hline OI & 0.41 & 80 & $\mathbf{0 . 0 1}$
\end{tabular}

Scale of reliability and validity coefficients. It is expected that there is a relatively high negative correlation between admission scale and non-admission scales. Mean correlation coefficient was 0.55 . Internal coefficient scale.

Table 2: Scale of reliability and validity coefficient

\begin{tabular}{cccc}
\hline Scales & OP & OI & $\mathbf{R}$ \\
\hline & 0.68 & -0.47 & -0.45 \\
\hline & & 0.56 & $\mathbf{0 . 4}$ \\
\hline & & & $\mathbf{0 . 2 8}$
\end{tabular}

\subsubsection{Revised Adult Attachment Scale (RAAS)}

This scale was first developed in 1990 by Callins \& Read and was revised in 1996. This questionnaire has three subscales, namely "Dependence" which indicates the level of confidence and dependence on others, "Closeness" that assesses sincerity and emotional closeness with others, and "Anxiety" that evaluates the concern of the individual for being rejected. Six terms are allocated to each of the subscales. Final retest coefficient of this test for each of the subscales, namely closeness, dependence and anxiety is reported at 0.68, 0.71 and 0.52 . Callins \& Read (1990; quoted by Hamidi., (2007) showed that closeness (C), dependence (D) and anxiety (A) remained stable within two months and even 8 months. Considering that the amounts of Cronbach's alpha are equal or higher than 0.80 in most cases, the level of obtained confidence is high. In ran, level of confidence by using test-retest method in terms of correlation of two performances with an interval of one month indicated that the difference of this test in a level of 0.95 is reliable.

\subsubsection{Child Attachment Assessment Scale (Q-Set)}

This questionnaire has 90 questions to assess attachment in children. The validity of this test was studied in a metaanalysis by Tabaeh Emami et al., (2011). Its predictor validity was obtained at 0.39 . Reliability of the questionnaire was calculated at 0.88 by retest. Internal consistency of the test was obtained at 0.83 by Cronbach's alpha and its validity was obtained at 0.27 simultaneous to Ainsworth strange situation (1989).

\subsubsection{Children Incompatible Schemas Questionnaire}

It has 40 items that evaluate 11 schemas in the children. The questions are designed for the children and refer to the common experiences in the life of children (Rijecbuar \& Debo, 2010; quoted by Ghamkharfard et al., 2012). The present questionnaire is obtained as the result of factor analysis of Yung schemas questionnaire with 75 questions. In that questionnaire, 11 subscales are considered to study 11 schemas in children. The subscales include loneliness (5 items), 
submission (5 items), mistrust/abuse (3 items), defectiveness (3 items), failure ( 3 items), vulnerability (6 items), undeveloped self ( 3 items), self-sacrifice ( 3 items), unrelent standards ( 3 items), entitlement ( 3 items), and insuf selfcontrol (3 items). Each item is marked by Likert 4-degree scale. In the study conducted by Rijecbuar \& Debo (2010; quoted by Ghamkharfard et al., 2012), reliability was calculate by retest method and average correlation of 0.67 was obtained for all the subscales. Validity in the aforesaid study was calculated through synchronization validity method by early adolescent temperament questionnaire-revised (EATQ-R); Ellis \& Rothbard (2001; quoted by Ghamkharfard et al., 2012) and a significant relation was obtained between internal variables of the two questionnaires (except for selfsacrifice and undeveloped self-subscales).

\subsubsection{Child abnormal symptoms inventory (CSI-4)}

It has been one of the common screening means for the most prevalent type of psychiatric disorders in children and its terms are formulated based on the standards of fourth edition of diagnostic and statistical guidebook of psychiatric disorders (DSM_IV). This list includes the symptoms of 21 behavioral and emotional disorders. Sensitivity and characteristics of this questionnaire was compared to an Iranian sample through the procedure of psychiatrist's diagnosis agreement based on different scores cutting scores and the best score was determined for each disorder. Sensitivity and characteristic for this test were obtained between $0.75-0.89$ and $0.91-0.97$, respectively. Reliability of this questionnaire by Tasnif method was calculated at 0.91 for the list of teachers and 0.85 for the list of parents. Validity of this questionnaire was obtained at 0.748 based on Cronbach's alpha. Terms of this questionnaire are prepared based on DSM-IV standards the validity of which has been determined by the experts of American Psychiatric Association. This questionnaire is scored by two methods, namely screening cut-off score method and symptom severity score method. In this research, symptom severity score method is used in the manner that the options "Never", "Rarely", "Sometimes" and "Most of the Times" are scored by codes 3, 2, 0, and 1, respectively. The last edition of Child abnormal symptoms inventory (CSI-4) has the lists of parents and teachers just like the former versions. In the present research, the list of parents of this test is used. This list has 79 terms. Child anxiety symptoms inventory is a part of Child abnormal symptoms inventory (CSI-4) that evaluates the symptoms of separation anxiety in children. It has 8 articles and its questions have been included in the anxiety disorder group of questionnaire.

\section{Data analysis}

Data analysis was made through calculation of Pearson correlation coefficients and SEM which was obtained by using AMOS@ version 18 software. Model parameters were estimated by ML method. For large samples, this method is based on deviation from normal.

\section{Results}

In this research, Pearson correlation coefficients were investigated between contributing variables in the model. Because of correlation between variables, the relations between variables can be explained by structural equation modeling. Table 3 results show correlation between children's attachment style and the score of separation anxiety in children is significant. Among subscales of children incompatibility schemas, un-relent standards, self-sacrifice, vulnerability and undeveloped self, have a significant correlation with separation anxiety in children. In other cases, there are correlations between most of the observed variables. Significance of these correlations allows for establishment of a structural model for observing the actual effects of variables on each other. 
Table 3: Correlation matrix of model indicators

\begin{tabular}{|c|c|c|c|c|c|c|c|c|c|c|c|c|c|c|c|c|c|c|c|c|}
\hline & 1 & 2 & 3 & 4 & 5 & 6 & 7 & 8 & 9 & 10 & 11 & 12 & 13 & 14 & 15 & 16 & 17 & 18 & 19 & $20 \quad 21$ \\
\hline Mother's Anxiety & 1 & & & & & & & & & & & & & & & & & & & \\
\hline Accepting children & -0.052 & 1 & & & & & & & & & & & & & & & & & & \\
\hline Excess protection & $0.097^{*}$ & $-0.266^{* \star}$ & 1 & & & & & & & & & & & & & & & & & \\
\hline Leniency & $0.144^{\star \star}$ & $-0.319^{* \star}$ & $0.412^{\star \star}$ & 1 & & & & & & & & & & & & & & & & \\
\hline Exclusion of children & 0.083 & $-0.378^{\star \star}$ & $0.478^{\star \star} 0$ & $0.442^{\star \star}$ & 1 & & & & & & & & & & & & & & & \\
\hline Closeness & -0.081 & -0.013 & -0.062 & 0.036 & -0.027 & 1 & & & & & & & & & & & & & & \\
\hline Dependence & -0.083 & 0.038 & -0.029 & -0.057 & -0.042 & $0.203^{* \star}$ & 1 & & & & & & & & & & & & & \\
\hline Anxiety & $0.239^{\star \star}$ & -0.031 & $0.131^{\star \star}$ & 0.083 & $0.152^{* *}$ & $-0.120^{* *}$ & -0.047 & 1 & & & & & & & & & & & & \\
\hline Ioneliness & $0.332^{\star \star}$ & -0.054 & $0.161^{\star \star} 0$ & $0.133^{\star \star}$ & 0.073 & -0.035 & -0.069 & $0.142^{\star \star}$ & 1 & & & & & & & & & & & \\
\hline submission & $0.347^{\star \star}$ & $-0.094^{\star}$ & $0.197^{\star \star} \mathrm{C}$ & $0.172^{\star \star} \mathrm{C}$ & $0.146^{\star \star}$ & -0.038 & -0.008 & $0.181^{\star *}$ & $0.672^{\star \star}$ & 1 & & & & & & & & & & \\
\hline mistrust/abuse & $0.214^{* *}$ & $-0.181^{\star *}$ & $0.288^{\star \star} 0$ & $0.244^{\star \star} c$ & $0.261^{* k}$ & -0.043 & $-0.088^{*}$ & $0.103^{*}$ & $0.468^{\star \star}$ & $0.460^{\star *}$ & 1 & & & & & & & & & \\
\hline defectiveness & $0.304^{\star \star}$ & 0.009 & $0.154^{\star \star}$ & 0.051 & $0.090^{*}$ & -0.053 & -0.074 & 0.051 & $0.484^{\star \star}$ & $0.416^{\star \star} 0$ & $0.368^{\star \star}$ & 1 & & & & & & & & \\
\hline failure & $0.266^{\star \star}$ & $-0.114^{\star \star}$ & $0.184^{\star \star} 0$ & $0.179^{\star \star} \mathrm{C}$ & $0.124^{* *}$ & 0.031 & 0.007 & $0.133^{\star \star}$ & $0.573^{\star \star}$ & $0.582^{\star \star} 0$ & $0.435^{\star *} \mathrm{C}$ & $0.442^{\star \star}$ & 1 & & & & & & & \\
\hline Vulnerability & $0.345^{* \star}$ & $-0.116^{* \star}$ & $0.201^{\star \star} 0$ & $0.201^{\star \star} \mathrm{C}$ & $0.128^{\star \star}$ & -0.023 & -0.064 & $0.154^{\star \star}$ & $0.540^{\star \star}$ & $0.518^{\star \star} 0$ & $0.453^{* \star} \mathrm{C}$ & $0.408^{\star \star} 0$ & $0.506^{\star \star}$ & * 1 & & & & & & \\
\hline Undeveloped self & $-0.115^{* \star}$ & -0.025 & -0.067 & 0.038 & -0.005 & 0.010 & 0.043 & 0.002 & -0.060 & -0.018 & 0.028 & $-0.100^{*}$ & -0.051 & 0.008 & 1 & & & & & \\
\hline Self-sacrifice & $-0.107^{\star}$ & $-0.137^{\star \star}$ & $0.105^{*}$ & $0.092^{\star}$ & $0.112^{\star}$ & 0.006 & 0.019 & -0.032 & 0.016 & 0.0790 & $0.205^{* k}$ & -0.021 & 0.040 & $0.177^{\star \star} 0$ & $0.315^{\star \star}$ & * 1 & & & & \\
\hline Un-relent standards & $0.109^{*}$ & $-0.087^{\star}$ & $0.145^{\star \star} 0$ & $0.120^{\star \star} \mathrm{C}$ & $0.118^{* *}$ & 0.013 & -0.039 & -0.003 & $0.315^{\star \star}$ & $0.281^{\star \star} 0$ & $0.342^{\star \star} \mathrm{C}$ & $0.240^{\star \star} 0$ & $0.303^{* \star}$ & ${ }^{*} 0.493^{\star \star} 0$ & $0.094^{*}$ & $0.342^{\star \star}$ & 1 & & & \\
\hline Competency & $0.133^{* \star}$ & -0.052 & $0.192^{\star \star} 0$ & $0.208^{\star \star} \mathrm{C}$ & $0.121^{\star \star}$ & -0.025 & -0.057 & 0.073 & $0.381^{* *}$ & $0.304^{\star \star} 0$ & $0.452^{\star \star} \mathrm{C}$ & $0.265^{\star \star} 0$ & $0.357^{\star \star}$ & ${ }^{\star} 0.400^{\star \star}$ & 0.039 & 0.067 & $0.366^{\star \star}$ & 1 & & \\
\hline insufficient self-control & $0.344^{\star \star}$ & -0.053 & $0.155^{\star \star} 0$ & $0.131^{\star *}$ & 0.073 & -0.029 & -0.008 & $0.163^{* \star}$ & $0.556^{\star \star}$ & $0.613^{\star \star} \mathrm{C}$ & $0.408^{* k}$ & $0.476^{\star \star} 0$ & $0.510^{\star \star}$ & ${ }^{*} 0.481^{* k}$ & -0.028 & 0.023 & $0.337^{\star \star} 0$ & $0.307^{\star *}$ & 1 & \\
\hline Children's attachment & 0.052 & 0.037 & -0.011 & 0.023 & -0.026 & 0.003 & 0.036 & -0.080 & 0.023 & 0.018 & 0.054 & -0.022 & 0.056 & $0.113^{\star \star} 0$ & $0.090^{*}$ & $0.199 * *$ & $0.146^{\star \star}$ & 0.0510 & 0.000 & 1 \\
\hline Separation anxiety & 0.047 & 0.006 & 0.005 & 0.012 & 0.002 & $-0.104^{*}$ & 0.005 & -0.042 & -0.010 & 0.0250 & $0.119^{\star *}$ & 0.033 & 0.054 & $0.097^{*}$ & 0.053 & 0.054 & 0.060 & 0.067 & 0.0320 & $0.302^{\star \star}$ \\
\hline
\end{tabular}

As it is observed in the fitted model, Coefficient 0.18 shows the effect of external variable "Maternal Anxiety" on the intermediary variable "Mother-Child Relation". Positive sign of this coefficient indicates a direct relation between maternal anxiety and mother-child relationship. Impact factor of mother-child relation on maternal attachment style is -0.09 which indicates a low but significant effect and despite a negative sign, it means a reverse relation between these two intermediary (internal) variables. The effect of mother-child relation on children's incompatibility schemas is 0.39 and indicates a direct relation between these two intermediary variables. Coefficient 0.14 shows the significant and direct effect of maternal attachment style on child's attachment style and coefficient 0.11 shows the effect of child's incompatibility schemas on child's attachment style. The effect of child's attachment style on the child's separation anxiety is high and is 0.34 .

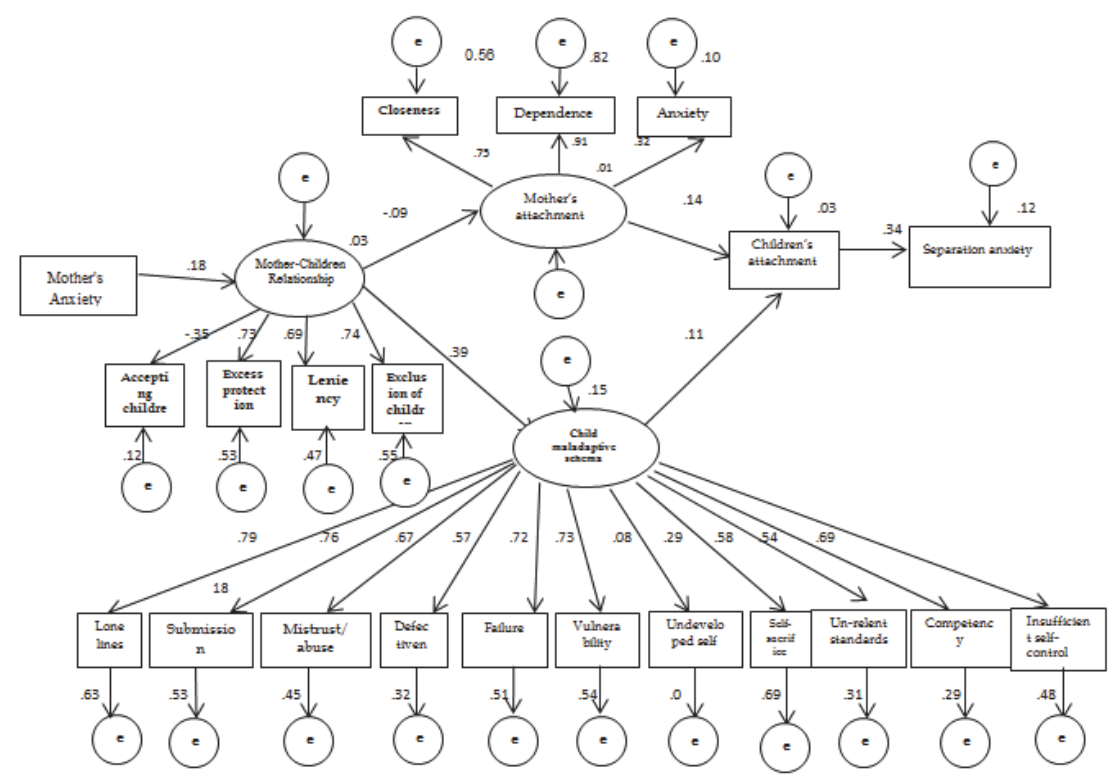

Figure 2: The fitted model with standard scores of separation anxiety in children, maternal anxiety, mother-child relation, maternal attachment style, child's incompatible schema and child's attachment style 
Table 4 which shows estimated coefficients, indicates significance of all the variables in the model. Review of subscales is as follows.

Subscales of "Mother-Child Relation": Mother-child relation has 4 subscales. Between these subscales, "Over Protection" followed by leniency scale have the highest effect.

Subscales of "Maternal Attachment Style": Maternal attachment style has 3 subscales which among them "Dependence" has the highest effect.

"Child's Incompatible Schemas" have 11 subscales among which "Loneliness", "Submission", "Mistrust/Abuse" and "Insufficient Self-control" subscales have the highest effect on the hidden variable of "Child's Incompatible Schemas" and finally on separation anxiety in children, respectively.

Table 4: Analysis of data and modeling by using SPSS and AMOS software packages

\begin{tabular}{|c|c|c|c|c|c|c|}
\hline Variables & & & Estimation & S.E & C.R & $\mathbf{P}$ \\
\hline Mother-Child Relation & $\leftarrow$ & Mother's Anxiety & 0.082 & 0.023 & 3.602 & 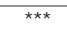 \\
\hline Child Maladaptive Schema & $\leftarrow$ & Mother-Child Relation & 0.124 & 0.018 & 6.962 & $\star \star \star ~$ \\
\hline Mother's attachment & $\leftarrow$ & Mother-Child Relation & -0.093 & 0.058 & -1.612 & $\star \star \star ~$ \\
\hline Children's attachment & $\leftarrow$ & Mother's attachment & 2.504 & 0.863 & 2.900 & 0.004 \\
\hline Children's attachment & $\leftarrow$ & Child Maladaptive Schema & 6.805 & 2.831 & 2.403 & 0.016 \\
\hline X61: Closeness & $\leftarrow$ & Mother's attachment & 1.000 & & & \\
\hline X62: Dependence & $\leftarrow$ & Mother's attachment & 1.252 & 0.158 & 7.922 & $\star \star \star ~$ \\
\hline X63: Anxiety & $\leftarrow$ & Mother's attachment & 0.390 & 0.058 & 6.669 & $\star \star \star *$ \\
\hline X54: Exclusion of children & $\leftarrow$ & Mother-Child Relation & 1.000 & & & \\
\hline X53: Leniency & $\leftarrow$ & Mother-Child Relation & 0.857 & 0.067 & 12.750 & $\star \star \star ~$ \\
\hline X52: Excess protection & $\leftarrow$ & Mother-Child Relation & 0.819 & 0.063 & 13.097 & 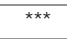 \\
\hline X51: Accepting children & $\leftarrow$ & Mother-Child Relation & -0.400 & 0.057 & -7.006 &  \\
\hline Separation anxiety & $\leftarrow$ & Children's attachment & 0.019 & 0.002 & 8.276 & 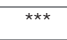 \\
\hline X711: Insufficient self-control & $\leftarrow$ & Child maladaptive schema & 1.000 & & & \\
\hline X710: Competency & $\leftarrow$ & Child maladaptive schema & 0.835 & 0.073 & 11.486 & $\star \star \star ~$ \\
\hline X79: Un-relent standards & $\leftarrow$ & Child maladaptive schema & 0.814 & 0.069 & 11.832 & $\star \star \star ~$ \\
\hline X78: Self-sacrifice & $\leftarrow$ & Child maladaptive schema & 0.430 & 0.069 & 6.270 & $\star \star \star *$ \\
\hline X77: Undeveloped self & $\leftarrow$ & Child maladaptive schema & 0.114 & 0.068 & 1.684 & $\star \star \star ~$ \\
\hline X76: Vulnerability & $\leftarrow$ & Child maladaptive schema & 1.988 & 0.129 & 15.367 & 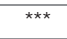 \\
\hline X75: Failure & $\leftarrow$ & Child maladaptive schema & 0.905 & 0.060 & 15.039 & $\star \star \star ~$ \\
\hline X74: Defectiveness & $\leftarrow$ & Child maladaptive schema & 0.677 & 0.056 & 12.035 & 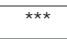 \\
\hline X73: Mistrust / Abuse & $\leftarrow$ & Child maladaptive schema & 0.993 & 0.070 & 14.206 & 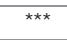 \\
\hline X72: Submission & $\leftarrow$ & Child maladaptive schema & 1.663 & 0.104 & 15.943 & $\star \star \star *$ \\
\hline X71: Loneliness & $\leftarrow$ & Child maladaptive schema & 1.547 & 0.094 & 16.483 & $\star \star \star$ \\
\hline
\end{tabular}

The most common statistical indexes for model goodness include Chi-square on freedom degree, square root of estimation, approximation error variance, comparative fit indexes (incremental fit index, comparative fit index). Chisquare, as an indicator for proper fitness with small amounts close to zero shows goodness of fit. The amount of Chisquare on freedom degree less than 5 indicates a desirable fit. The amount close to 1 for incremental and comparative fit indexes, the amount smaller than or equal to 0.05 for square root indexes of estimation of approximation error variance indicate desirability of fit. Considering the amount of Chi-square obtained from model fit and freedom degree being 186 and 537.54, respectively, and since division of these two figures by each other gives a sum of 2.89 (smaller than 3), the model is statistically significant ( $P$ value $=0.00$ ). RMSE is smaller than 0.08 . This indicates that mean square root of error is suitable for the model. Relative fit index is 0.741 . The more this amount is closer to 1 , the more it indicates better capability of fitted model on the data. Tucker-Lewis Index (TLI), NFI index, and Incremental Fit Index have been calculated higher than 0.9 . This is an indication of validity of the fitted model and that it is an ideal model.

Table 5: Indexes of goodness of fit of SEM for separation anxiety

\begin{tabular}{cccccccccc}
\hline Index & Chi-square & df & P-value & RMSE & RFI & TLI & NFI & IFI & CFI \\
\hline Calculated & 537.54 & 186 & 0.000 & 0.076 & 0.741 & 0.910 & 0.9 & 0.92 & 0.901 \\
\hline
\end{tabular}


Table 6: Results of execution of structural model for research variables

\begin{tabular}{cllr}
\hline Path No. & Path & Results \\
\hline 1 & Mother's Anxiety -----> Mother-Child Relation ------> Mother's attachment ------> Child attachment -------> Child Separation Anxiety & Confirmed \\
\hline 2 & Mother's Anxiety -----> Mother-Child Relation -----> Child maladaptive schema ----> Child attachment ------> Child Separation Anxiety & Confirmed \\
\hline
\end{tabular}

Considering table 5 , IFI and significance of P-value, there is statistically a causal significant relation in two directions. In table 6 therefore, these two directions have separated and include maternal anxiety with a coefficient of 0.18 influencing on mother-child relation, mother-child relation influencing on maternal attachment style with a coefficient of -0.09 , maternal attachment style with a coefficient of 0.14 influencing on child's attachment style and finally, child's attachment style with a coefficient of 0.34 influencing on child's separation anxiety with a coefficient of 0.34 . Maternal anxiety has an indirect effect on the child's separation anxiety though mother-child relation, maternal attachment style and child's attachment style. In the second direction, mother's anxiety influences on mother-child relation, mother-child relation with a coefficient of 0.39 influences on child's incompatible schemas, child's incompatible schemas influences on child's attachment style with a coefficient of 0.11 and finally, child's attachment style influences on child's separation anxiety. Mother's anxiety in the second direction directly affects child's separation anxiety through mother-child relation, child's incompatible schema and child's attachment style.

\section{Discussion and Conclusion}

In order to identify effective factors on separation anxiety in children and study of its relationship with separated variables, the present research was conducted with the goal of formulating a causal model for separation anxiety in children based on variables including maternal anxiety, mother-child relation, maternal attachment style, child's incompatible schemas and child's attachment style.

The results indicate that the model was confirmed and that it was a relatively good and fitted model which can be relied upon to explain separation anxiety in children. Considering the two obtained routes in the model, the first route shows that the effect of external variable of maternal anxiety on the intermediary variable of mother-child relation with a coefficient of 0.18 and maternal anxiety has a direct and positive effect on mother-child relation. Among 4 subscales in mother-child relation factor, over protection, leniency and exclusion of child scale had the highest effect and forth subscale, admission of child had a negative effect on the variable of mother-child relation. In this way, there is a positive and significant correlation $(a<0.01)$ between maternal anxiety and subscales including over protection and leniency. The effect of maternal anxiety on mother-child relation has also been confirmed in studies conducted by Khodapanahi et al., (2012). Findings of the aforesaid research have indicated that mother-child conflict is a positive predictor of anxiety sign. In this way, Oliver et al., (2009); Hassanabadi et al., (2012) showed in their researches that a parent-child relation-based treatment influences on the improvement and decrease of anxiety. These findings are in line with those of the present study. Impact coefficient of mother-child relation on maternal attachment style is -0.09 which indicates little but significant effect and despite a negative sign, it means that there is an inverse relation between these two intermediary (internal) variables; i.e., the more leniency, over protection and admission are in the mother-child relation, the more insecure will be maternal attachment.

From among subscales of maternal attachment style, dependence has the highest effect on the child's attachment style by influencing on the hidden variable of maternal attachment. Moreover, a coefficient of 0.14 indicates the significant and direct effect of maternal attachment style on child's attachment style. This finding is in line with the study conducted by Khodapanahi et al., (2012). Researches have indicated that maternal insecure attachment is the positive predictor of child's separation anxiety with the intermediation of child's insecure attachment style (Brotherson., 2006) which is formed based on the initial attachment experiences and influences on other relations and results in emotional adjustment, selfcontrol and problem solving skills. According to the findings of Aslani et al., (2013); Megam \& Sichti (2002); Ratro \& Izenburn., 2010) concerning the fact that lack of any opportunity for attachment formation will result in two clinical models of attachment disorder and also considering that insecure attachment is directly related to disorders such as anxiety, parental attachment enhances children's attachment and provides the ground for child's perception that this world is a dangerous place. Findings of Barber (1996) study showed that maternal attachment along with over protection induces this message to the child that he/she is unable to face challenging situations. In this way, she feels insecure and intensifies the child's anxiety. With a view to these studies and researches, it can be concluded that maternal insecure attachment can be one of the factors contributing in insecure attachment and separation anxiety in children. These findings are in line with the results of the present study. 
Moreover, in this route it is observed that child's attachment style has a direct effect on his/her separation anxiety with a coefficient of 0.34 . Therefore, it can be said that insecure attachment of the child increases his/her separation anxiety. Moreover, according to the findings of Zolfaghari Motlagh et al., (2008), children with ambivalent insecure attachment styles are vulnerable of separation anxiety disorder. Their being in line with the findings of the present study confirms the explanation of first route of structural model. Theoretically, by relying on Bowlby (1969) theory of attachment, it can be said that the best concept to explain separation anxiety is the concept of attachment because in fact, the child suffering from separation anxiety suffers lest he misses his mother. Insecure attachment clearly states the same state. Therefore, this route in the model enjoys both theoretical and practical support.

The second route shows that maternal anxiety with a coefficient of 0.18 has a direct effect on mother-child relation. In the growth model of Manasis et al., (1994), parental behavior such as over control, excess support modeling or enhancement of anxiety or avoidance behavior, negative beliefs and expectations from the child, non-admission, rejection and criticism is emphasized. These findings are in line with those of the present study. Moreover, there is a significant relation between mother-child relation and all children's incompatible schemas. Noee et al., (2010) found parental roots for incompatible schemas. Those parents who do not let their child declare his/her viewpoint and avoid manifestation of child's internal emotions and feelings, their children will be anxious and agitated in the future with incompatible schemas (Cai-Lian et al., 2012).

In this way, positive effect of internal variable of child's incompatible schemas with an effect on the intermediary variable of child's attachment style with a coefficient of 0.11 and then by affecting the dependent variable of child's separation anxiety with a coefficient of 0.34 are quite evident. This finding is in line with the findings of Cai-Lian et al., (2012). It should be noted that from among 11 subscales, child's incompatible schemas, loneliness, submission, mistrust/abuse, and unstuffy self-control have the highest effect on the hidden variable of child's incompatible schemas and finally on the child's separation anxiety. This result is in line with the findings of Ghamkharfard et al., (2012). Findings of the aforesaid research showed that childhood anxiety is predicted by schemas of failure, vulnerability, loneliness and submission of children. Moreover, these studies showed that children's schemas have a more outstanding role in anticipation of childhood anxiety. Chorpita \& Barlo., (2004; quote by Aliov et al., 2012) believe that two dimensions of maternal behavior including warmness or sensitivity children and stable responding and also encouragement of children to independence and secure attachment will facilitate control feelings of children and decrease of their anxiety. Findings of the present study and those of previous researches emphasize on the dependent variable. In general, IFI higher than 0.9 indicates the validity of the fitted model and shows that the model is an ideal one. Therefore, IFE and findings of the previous researches indicate a significant causal relation in routes 1 and 2.

Findings of the present study are in line with theoretical and practical records and indicate that maternal anxiety influences on separation anxiety in children. This effect is made through intermediation of four variables including motherchild relation, maternal attachment style, children's incompatible schemas, and child's attachment style. Review of the role of intermediaries in the study of separation anxiety is of a great importance. On this basis, making effort in parallel with offering health and training services to mothers towards promotion of self-awareness and welfare psychological improvement of mother and mother-child relation in the first step plus arranging for corrective measures to change maternal attachment style, attachment style and incompatible schemas of children can decrease separation anxiety disorders. In the theoretical level, the results of the present study confirmed the relation between the aforesaid variables and set forth new questions. Is the proposed model the same among gender and age groups? Therefore, it is suggested that the next studies review the proposed model by using multi-group structural equation model so that the aforesaid model is shifted towards a higher comprehensiveness. Moreover, review of the similar model with variables associated to child's separation anxiety should be addressed. It is recommended that researchers review the relations of the proposed model by inclusion of variables related to father and in other populations especially single-child families and other socioeconomic and cultural conditions.

Although the present study provided evidences concerning the intermediary role of the aforesaid variables, it had some limitation. One of those limitations is the use of correlation plan and a causal interpretation of its results may face limitations. The second restriction was the self-reporting feature of research tools that showed the results of limitation of the participant from the measured structures. The measured structures may be influenced by different cultural, individual and family values. It is recommended that the next researches make more use of those procedures addressing the cause and effect relation and also use other measurement procedures. In addition, they should use structures which are less influenced by cultural values or they should standardize them. 


\section{Acknowledgements}

The Authors would like to appreciate helps of all subjects and research who kindly helped us during development of research. author would like to acknowledge Dr sholeh Amiri contributions in various stages of the literature review process and an earlier draft of the paper, as well as the statistical advice provided by Dr Houshang Talebi. The authors also thank $\mathrm{Dr}$ afshin safaee for their assistance in cross-checking some of the data extraction. We also would like to appreciate for proof reading of current manuscript.

\section{References}

Abbasi, M., Neshatdoost, H., Aghamohammadian Sherbaft, H., 2010. Effectiveness of child's parent interaction treatment on the decrease of the signs of separation anxiety disorder. Journal of clinical psychology, second year, 2, 47-57.

Ainsworth, M., 1989. Attachments beyond infancy. American Psychologist.

Aliov, M., Sharifi, M., Ghafelehbashi, H., 2012. Therapeutic techniques for comprehensive anxiety disorder (behavioral-cognitive approach and drug therapy). Tehran: Nivand.

Apetroaia, A., Hill, C., Creswell, C. 2015. Parental responsibility beliefs: associations with parental anxiety and behaviours in the context of childhood anxiety disorders. Journal of Affective Disorders,188, 127-133.

Arizi, H., Farahani, H.. 2008. Applied methods of research in clinical psychology and consultation. Tehran: Danzheh.

Aslani, K.h., Ghamari, M., Ramezani, S.H., Khabbazi, M. 2013. Testing the model of attachment to parents with anxiety and depression and with the intermediation of attachment to God. family consultation and psychotherapy, 3, 420-437.

Babaei, A., Golestani Bakht, T., Yaghoobi, Gh., 2008. Review of the relation between maternal personality dimensions and anxiety in children. Journal of educational psychology studies, 5, 1, 2-14.

Barber, B. 1996. Parental psychological control: Revisiting a neglected construct. Child Dev. 67,19-32.

Barra, F., Vicente, B., Saldivia, S., Melipillan, R., 2014. Separation Anxiety, Social Phobia and Generalized Anxiety Disorders in the Chilean Epidemiological Study of Children and Adolescents. J Child Adolesc Behav, 2, 133-140, doi.org/10.4172/23754494.1000133

Berk, L., 2001. Psychology of Growth. Translated by Yahya Seyed Mohammadi, 2007, Tehran: Arasbaran.

Besharat, M., 2004. A survey on the relation of parents' idealism and examination anxiety in children. Journal of psychology and educational sciences, 34, 1-19

Bowlby, J., 1969.Attachment and loss: Attachment. Vol.1, NewYork: Basic Books.

Brotherson, Sean., 2006. Keys to Building Attachment with young children, Family Science Specianst. 4. 13-27.

Cai-Lian, T.. Amanda, C,. Amudha, K,. Yoon-Ting, K., 2012. Parenting Styles and Self-Efficacy of Adolescents: Malaysian Scenario. Global Journal of Human Social Science arts \& Humanities, 12, 1-8.

Cavasagar, V. M et al., 2000."Parent Child Concordance for Separation Anxiety: A Clinical Study". Journal of Affective Disorders, 65, 8184.

Chorpita B.F., et al., 1998. Perceived Control as a Mediator of Family Environment in Etiological Models of Childhood Anxiety. Journal of Behaviour Therapy, 29, 457-476.

Chorpita, B. F.,Yim, L. M., Donkervoet, J. C., Arensdorf, A., Amundsen, M. J., McGee, C., Errano, A., Yates, A., morelli, P. 2002.Toward large-Scale implementation of empirically supported treatments for children :A review and observations by the Hawaii Empirical Basis to Services Task Force. Clinical Psychology: Science and Practice, 9.165-190.

Ganji, H., 2001. Evaluation of personality. Tehran: Savalan.

Ghamkharfard, Z., Amrollahninia, M., Azad Fallah, P., 2012. A survey on the childhood anxiety predictors based on child's incompatible schemas and maternal parenting styles. Journal of behavioral sciences, 6, 253-262.

Hamidi, F., 2007. A survey of the relation between attachment styles and marital satisfaction among married students of teaching. Family study quarterly journal, 25, 9-33.

Hassanabadi, H., Asghari Nekah, M., Tabibi, Z., 2012. A survey on effectiveness of child-parent based game therapy (CPRT) on parenting styles. J Behavioral Sciences,1, 473-489.

Hazen, C., Shaver, P. R., 1994. Attachment an organizational framework for research on close relationship. Psychological Ingenuity, 22, 1-5.

Hewitt, P. L., Flett, G. L., 2004.The Cognitive And Treatment Aspects Of Perfectionism. Journal of Rational-Emotive \& Cognitive Behaviour Therapy, 22, 233-240.

Hooman, H. 2001. Analysis of multivariable data in behavioral research. Tehran: Parsa publications.

Khodapanahi, M., Ghanbar, S., Nadali, H., Seyed Mowlavi, P., 2012. The quality of mother-child relation and anxiety sign in preschool children. Journal of evolutionary psychology: Iranian psychologists, 33, 5-13.

Lotfi kashani, F., Vaziri, S. h., 2010. Psychopathology of children. Tehran: Arasbaran.

Murray, C., Johnstion, C., 2006. Parenting in mothers with and without attention-deficit/hyperactivity disorder. Journal of Abnormal Psychology, 115, 52-61.

Noee, Z., Asgharnejad Farid, A., Fati, L., Ashoori, A., 2010. Comparison of initial incompatible schemas and their parental roots in those suffering from obsessive-compulsive personality, obsessive-compulsive disorder and non-clinical team. Journal of new issues of 
cognitive sciences, $12,59-69$.

Oliver. P., Wright Guerin. D., Coffman. J., 2009. Big five parental personality traits, parenting behaviours. And adolescent behaviour problems: A mediation model. Personality and Individual Differences, 47, 631-636.

Rutter, M., Eisenberg. 2010. Temperament. In Handbook of child psychology.vok.3.Social, emotional, and personality development (pp.99-166). New York: Wiley.

Tabaeh Emami, Sh., Nouri, A., Malekpoor, M., Abedi, A., 2011. Effectiveness of cognitive behavioral training of mothers on the change of maternal behavior and insecure attachment of the child. Journal of clinical psychology , third year, 11, 7-15.

Turner, K., Sander, M. 2006. Dissemination of evidence-based parenting and family support strategies: Learining from the triple Positive Parenting Program system approach. Aggression and Violent Behavior. 11, 176-19.

Waite, P., Creswell, C., 2014. Children and adolescents referred for treatment of anxiety disorders: Differences in clinical characteristics. Journal of Affective Disorders, $167,329,322$.

Waite, P., Creswell, C., 2015. Observing Interactions between Children and Adolescents and their Parents: The Effects of Anxiety Disorder and Age.J Abnorm Child Psychol, 43,1079-1091. DOI 10.1007/s10802-015-0005-z.

Warner, C. M., Reigada, .C., Fisher, P. h., Saborsky, A. L., Benkov, K. J., 2009. CBT for anxiety and associated somatic complaints in pediatric medical setting: An open pilot study. Journal of Clin Psychol Mmed Setting, 16,169-177.

Yapa, M. B. H., Jorm, A. F., 2015. Parental factors associated with childhood anxiety, depression, and internalizing problems: A systematic review and meta-analysis. Journal of Affective Disorders,175, 424-440.

Zamiri, R., 2005. A survey of the relation between type of delivery and mother-child emotional relation in preschool girls (kindergartens licensed by welfare organization of Mashhad city), Islamic Azad University, Roodehen campus.

Zolfahgari Motlagh, M., Jazayeri, A., KHooshabi, K., Mazaheri, M., Karimloo, M., 2008. Effectiveness of attachment-based treatment on decrease of the signs of separation anxiety disorder. Journal of psychiatrics and clinical psychology of Iran, 40,380-388. 